\title{
REVIEW ARTICLE OPEN Carbon dioxide levels in neonates: what are safe parameters?
}

\author{
Sie Kei Wong ${ }^{1}$, M. Chim ${ }^{1}$, J. Allen ${ }^{1,2}$, A. Butler ${ }^{1}$, J. Tyrrell ${ }^{1}$, T. Hurley ${ }^{1}$, M. McGovern ${ }^{1}$, M. Omer ${ }^{1,3}$, N. Lagan $^{1,2}$, J. Meehan $^{1,2}$, \\ E. P. Cummins ${ }^{4}$ and E. J. Molloy ${ }^{1,2,3,5}$
}

There is no consensus on the optimal $\mathrm{pCO}_{2}$ levels in the newborn. We reviewed the effects of hypercapnia and hypocapnia and existing carbon dioxide thresholds in neonates. A systematic review was conducted in accordance with the PRISMA statement and MOOSE guidelines. Two hundred and ninety-nine studies were screened and 37 studies included. Covidence online software was employed to streamline relevant articles. Hypocapnia was associated with predominantly neurological side effects while hypercapnia was linked with neurological, respiratory and gastrointestinal outcomes and Retinpathy of prematurity (ROP). Permissive hypercapnia did not decrease periventricular leukomalacia (PVL), ROP, hydrocephalus or air leaks. $\mathrm{As}_{\mathrm{s}}$ safe $\mathrm{pCO} \mathrm{C}_{2}$ ranges were not explicitly concluded in the studies chosen, it was indirectly extrapolated with reference to $\mathrm{pCO}_{2}$ levels that were found to increase the risk of neonatal disease. Although $\mathrm{PaCO}_{2}$ ranges were reported from 2.6 to $8.7 \mathrm{kPa}(19.5-64.3 \mathrm{mmHg})$ in both term and preterm infants, there are little data on the safety of these ranges. For permissive hypercapnia, parameters described for bronchopulmonary dysplasia (BPD; $\mathrm{PaCO}_{2} 6.0-7.3 \mathrm{kPa}: 45.0-54.8 \mathrm{mmHg}$ ) and congenital diaphragmatic hernia $(\mathrm{CDH} \mathrm{PaCO} 2 \leq 8.7$ $\mathrm{kPa}: \leq 65.3 \mathrm{mmHg}$ ) were identified. Contradictory findings on the effectiveness of permissive hypercapnia highlight the need for further data on appropriate $\mathrm{CO}_{2}$ parameters and correlation with outcomes.

Pediatric Research (2022) 91:1049-1056; https://doi.org/10.1038/s41390-021-01473-y

\section{IMPACT:}

- There is no consensus on the optimal $\mathrm{pCO}_{2}$ levels in the newborn.

- There is no consensus on the effectiveness of permissive hypercapnia in neonates.

- A safe range of $\mathrm{pCO}_{2}$ of 5-7 kPa was inferred following systematic review.

\section{INTRODUCTION}

Carbon dioxide $\left(\mathrm{CO}_{2}\right)$ is a physiological gas produced as a consequence of aerobic metabolism. Plasma $\mathrm{CO}_{2}$ levels are tightly regulated under physiological conditions to maintain blood $\mathrm{pH} . \mathrm{CO}_{2}$ is mainly removed from the body via the lungs and can accumulate in lung pathologies. In humans, normocapnia is defined as a $\mathrm{pCO}_{2}$ of between 4.7 and $6.0 \mathrm{kPa}(35.3-45.0 \mathrm{mmHg})$, with $\mathrm{pCO}_{2}$ reflecting the balance between $\mathrm{CO}_{2}$ production and removal. Consequently, slightly higher $\mathrm{pCO}_{2}$ values are associated with the venous circulation as $\mathrm{CO}_{2}$-enriched blood is returned towards the lungs. ${ }^{1}$ Importantly, the local microenvironment of cells and tissues can experience $\mathrm{pCO}_{2}$ levels that differ markedly from systemic $\mathrm{PaCO}_{2}$, e.g., in solid tumours. ${ }^{2}$ This is likely a consequence of local metabolic activity and alterations in local blood supply. Adaptive responses to changes in $\mathrm{CO}_{2}$ can be classified as being acute or chronic. Acute responses to $\mathrm{CO}_{2}$ are generally sensed through brain stem central chemoreceptors that modulate the rate and depth of breathing to try and maintain normocapnic partial pressures of $\mathrm{CO}_{2}$. Chronic responses to $\mathrm{CO}_{2}$ can be elicited on a cellular level through $\mathrm{CO}_{2}$-dependent changes in gene expression, e.g., genes associated with immune signalling. ${ }^{3}$ The cerebral vasculature is very sensitive to physiological gases. Given the brain's significant demand for oxygen to maintain normal function, several adaptive cerebral vasodilatory mechanisms are elicited to promote and maintain cerebral blood flow under conditions of hypoxia. Elevated $\mathrm{CO}_{2}$ levels, which are frequently associated with hypoxia, also promote an increase in cerebral blood flow through dilation of cerebral arteries and arterioles. ${ }^{4}$ In contrast, hypocapnia leads to vascular constriction and reduced blood flow. Thus, the cerebral vasculature is highly sensitive to the level of circulating physiological gases with hypocapnia and hypercapnia capable of affecting brain oxygen levels indirectly through modulation of cerebral blood flow.

In healthy neonates, the physiological $\mathrm{CO}_{2}$ range is defined as 4.7-6.0 kPa (35.3-45.0 mmHg). ${ }^{5,6}$ Given the physiological impact of $\mathrm{CO}_{2}$ levels on cerebral vasculature and the impact of $\mathrm{CO}_{2}$ on immune signalling, it has been suggested that hyper- and hypocapnia can both have detrimental effects for newborn infants. While $\mathrm{CO}_{2}$ monitoring can be undertaken on a continuous basis or intermittently with blood gas measurement, there is currently no consensus on the optimal $\mathrm{pCO}_{2}$ levels in the newborn. Similarly, there is limited evidence as to what is clinical best-practice with respect to managing the care of neonates with moderate hypocapnia and hypercapnia.

\footnotetext{
${ }^{1}$ Department of Paediatrics, School of Medicine, Trinity College, The University of Dublin, Trinity Translational Medicine Institute (TTMI) \& Trinity Research in Childhood Centre (TRiCC), Dublin, Ireland; ${ }^{2}$ Childrens Hospital Ireland (CHI) at Tallaght, Tallaght University Hospital, Dublin, Ireland; ${ }^{3}$ Department of Neonatology, Coombe Women's and Infant's

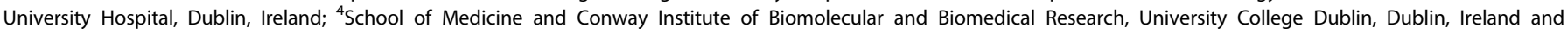
${ }^{5}$ Neonatology, $\mathrm{CHI}$ at Crumlin, Dublin, Ireland

Correspondence: E J. Molloy (Eleanor.molloy@tcd.ie)
}

Received: 26 March 2020 Revised: 1 March 2021 Accepted: 2 March 2021

Published online: 6 July 2021 


\section{Effects of hypocapnia}

Hypocapnia in the neonate may be the result of a disease such as transient tachypnoea of the newborn, or more commonly, induced iatrogenically during mechanical ventilation or extracorporeal membrane oxygenation. ${ }^{5}$ Permanent brain injury may be caused by cerebral vasoconstriction and low cerebral tolerance of hypoxia, ${ }^{7,8}$ and hypocapnia may worsen ischaemia/reperfusioninduced acute lung injury. ${ }^{6}$ There is a correlation between the degree and duration of hypocapnia and the incidence and severity of these lesions. ${ }^{7}$ In both term and preterm neonates, hypocapnia can therefore be a risk factor for central nervous system damage which may manifest as cerebral palsy (CP), cognitive or developmental disabilities, intraventricular haemorrhage (IVH), periventricular white matter injury and auditory impairment. $5,6,9,10$

\section{Effects of hypercapnia}

Autoregulation of cerebral blood flow and subsequent cerebral oxygenation is undermined when $\mathrm{pCO}_{2}$ levels increase. ${ }^{11}$ Severe hypercapnia is of concern due to the risk of cerebral oedema and vasodilation, particularly in relation to infants with neonatal encephalopathy (NE). ${ }^{12}$ High $\mathrm{PaCO}_{2}$ predisposes preterm infants to $\mathrm{IVH}^{9,10,12,13}$ and maximum $\mathrm{pCO}_{2}$ seems to be an important factor for severe IVH in the first three postnatal days. ${ }^{14}$ Severe hypercapnia alters consciousness and mental state, induces spasms and suppresses cortical activity, which is associated with impaired outcome in preterm infants. ${ }^{6,15}$ There is also a significant association between hypercapnia in low weight infants and bronchopulmonary dysplasia (BPD) as compared to normocapnic controls. $^{16}$

A greater prevalence of necrotising enterocolitis (NEC) was observed in premature neonates with a higher $\mathrm{pCO}_{2}$ target $(7.3-10.0 \mathrm{kPa}=54.8-75.0 \mathrm{mmHg})$ as compared to the normal target group. ${ }^{17}$ Neonatal survival rate was associated with the level of $\mathrm{PaCO}_{2}$ in patients with congenital diaphragmatic hernia $(\mathrm{CDH})$. Infants with $\mathrm{CDH}$ that remained hypercapnic postresuscitation $(9.6 \pm 2.5 \mathrm{kPa}=72.0 \pm 18.8 \mathrm{mmHg})$ had a worse prognosis as compared to those who were normocapnic. ${ }^{18}$ However, it is important to note that this observation may be explained by the severity of lung hypoplasia, with more severe hypoplasia manifesting as persistent hypercapnia.

The need for mechanical ventilation in the neonatal period has been associated with lung injury and long-term respiratory morbidity such as BPD. ${ }^{19,20}$ There is also a higher risk of premature brain injury such as periventricular leukomalacia (PVL) and IVH associated with its use. ${ }^{10,21}$ The duration and intensity of ventilation has been implicated in the pathogenesis of neonatal lung injury ${ }^{22}$ with large tidal volumes and resultant volutrauma being especially damaging to the immature lung. ${ }^{22}$ Permissive hypercapnia is a ventilatory strategy that permits relatively high levels of $\mathrm{CO}_{2}$ in ventilated neonates, thereby allowing lower tidal volumes to be used in patients who are mechanically ventilated. This less aggressive approach to ventilation reduces the risk of volutrauma in ventilated neonates and may improve respiratory outcomes and survival rates. Effective $\mathrm{CO}_{2}$ elimination can occur at lower tidal volumes and peak inspiratory pressures as increased $\mathrm{PaCO}_{2}$ achieved using permissive hypercapnia increases $\mathrm{CO}_{2}$ elimination for the same minute ventilation (from the equation $k \times \mathrm{VCO}_{2}=\mathrm{PaCO}_{2} \times \mathrm{Va}$, with $V a$ representing alveolar ventilation). Hypercapnic acidosis also improves ventilation-perfusion mismatch and allows greater unloading of $\mathrm{O}_{2}$ at the tissues (Bohr effect). In addition, there is also an increased respiratory drive to reduce apnoea and increased cardiac output. ${ }^{23,24}$ Thus, it has been widely employed in the ventilation of preterm infants. We aimed to determine safe $\mathrm{pCO}_{2}$ levels in neonates with reference to the potential side effects of hypercapnia and hypocapnia identified within this population.

\section{METHODS}

Literature search

The methodology of this systematic review was designed and conducted in accordance with the Preferred Reporting Items for Systematic Reviews and Meta-Analyses (PRISMA) statements ${ }^{25}$ and guidelines from the Meta-analysis of Observational Studies in Epidemiology (MOOSE). ${ }^{26}$ A literature search was done on Pubmed, Embase and Scopus and the terms undertaken were: "neonates" AND ("hypocapnia" OR "hypercapnia"). Additional studies identified during a manual search were also included.

\section{Inclusion and exclusion criteria}

Studies that satisfied the following criteria were included into our literature review: (1) full text available in English, (2) human subjects and (3) peer-reviewed journals. Exclusion criteria were established to eliminate studies beyond the scope of the review: editorials; letters and case reports; duplicate publications; and use of animal models. The publication years were not restricted due to a limitation in the number of studies available.

\section{Quality assessment and data extraction}

In the first phase of selection, the titles and abstracts were reviewed by two independent reviewers to determine their relevance. Disagreements were either resolved by a third reviewer or settled by consensus. The second phase of selection involved full text screening where an independent reviewer determined their eligibility. Covidence online software ${ }^{27}$ was employed in both phases of screening to streamline the relevant articles. Data extracted includes (1) side effects of hypercapnia, hypocapnia and permissive hypercapnia(2) $\mathrm{pCO}_{2}, \mathrm{PaCO}_{2}$ or $\mathrm{PcCO}_{2}$ levels and (3) population characteristics. Analysis was subsequently performed, and results were tabulated according to preterm and term termed neonates (Tables 1 and 2). As safe $\mathrm{pCO}_{2}$ ranges were not explicitly concluded in the studies chosen, it was indirectly extrapolated with reference to $\mathrm{pCO}_{2}$ levels that were found to increase the risk of neonatal disease. The data were then categorised based into pre-term termed and term termed infants. The quality of the studies was assessed using the hierarchy of evidence. ${ }^{28}$

\section{RESULTS}

Two hundred and ninety-nine studies were identified via database searching and 18 additional studies were identified through manual searching. There were 261 papers after duplicates were removed. Seventy-seven full-text articles remained after the first round of screening and 37 studies were included in this review (Fig. 1).

\section{Preterm infants}

Hypocapnia. Brown et al. reviewed the range of permissive hypercapnia used in clinical practice and determined the relationship between $\mathrm{PaCO}_{2}$ and $\mathrm{pH}$ during the first three days of life and negative health outcomes. Their subjects were 147 premature neonates who were less than 32 weeks gestational age. Preterm infants of less than 29 weeks gestational age had a higher risk of severe IVH and PVL if their $\mathrm{PaCO}_{2}$ fell below $4.0 \mathrm{kPa}(30.0 \mathrm{mmHg})$ within the first two days of life. Similarly, if the same group of infants had at least $3 \mathrm{PaCO}_{2}$ values less than $4.0 \mathrm{kPa}(30.0 \mathrm{mmHg})$ within the first day of life they were at increased risk of BPD ( $p=$ 0.036). ${ }^{9}$

Liu et al. ${ }^{5}$ prospectively found a significantly higher incidence of $\mathrm{PVL}$ in premature newborns with hypocapnia $\left(\mathrm{PaCO}_{2} \leq 4.67 \mathrm{kPa}=\right.$ $35.0 \mathrm{mmHg}$ ) as compared to the preterm control group, suggesting that hypocapnia is an important high-risk factor for PVL. A prospective study by Collins et al. which involved 1105 infants with birth weight between 500 and $2000 \mathrm{~g}$ found that the unadjusted univariate rates of disabling $C P$ within ventilated infants by quintile of cumulative hypocapnia exposure has a 


\begin{tabular}{|c|c|c|c|c|c|c|c|c|c|c|c|c|c|c|c|c|c|}
\hline 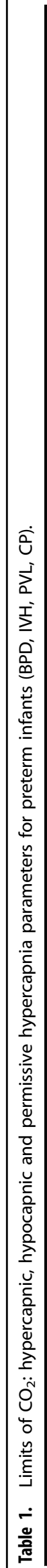 & 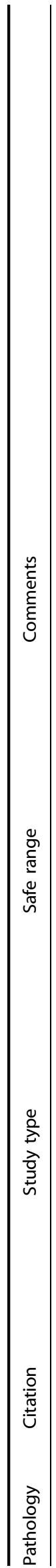 & 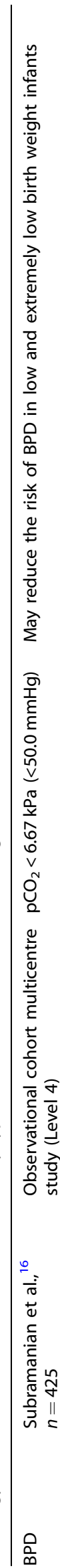 & 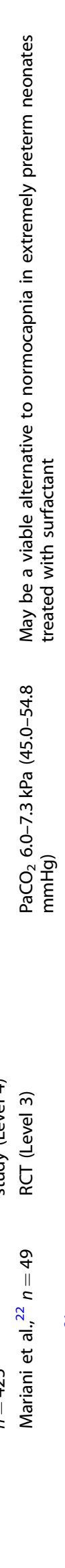 & 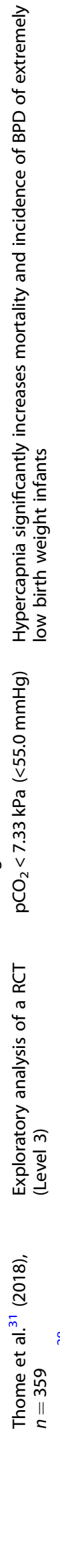 & 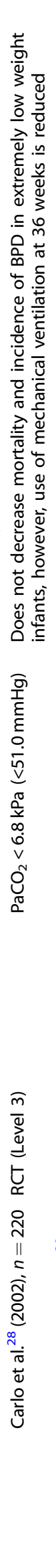 & 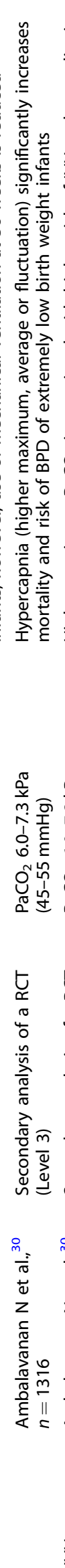 & 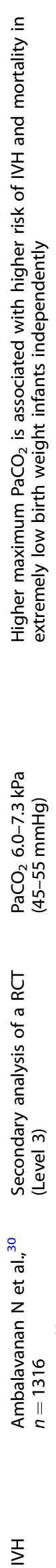 & 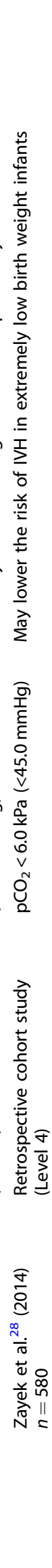 & 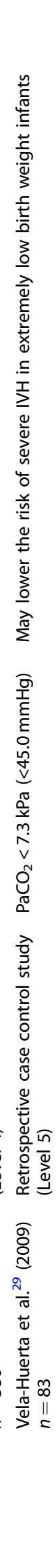 & 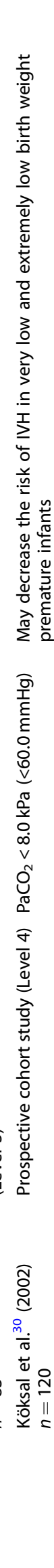 & 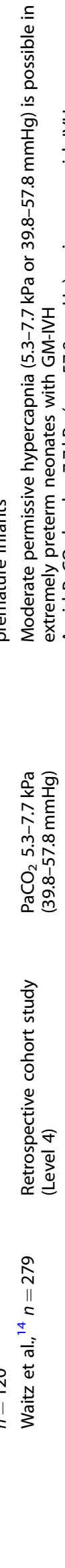 & 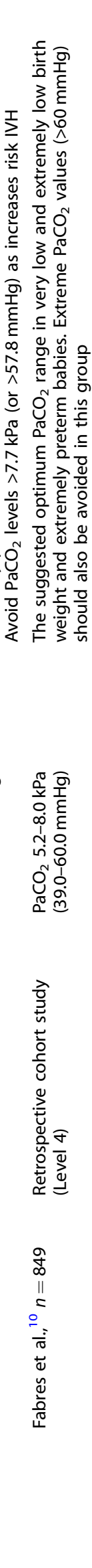 & 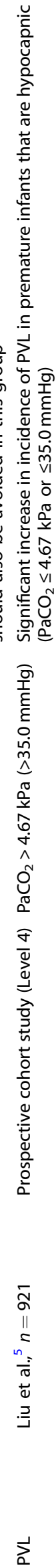 & 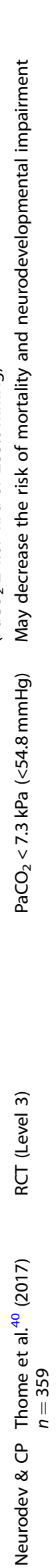 & 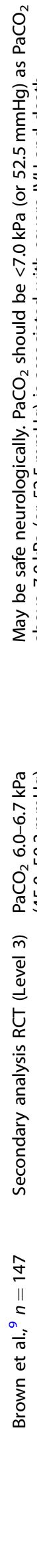 & 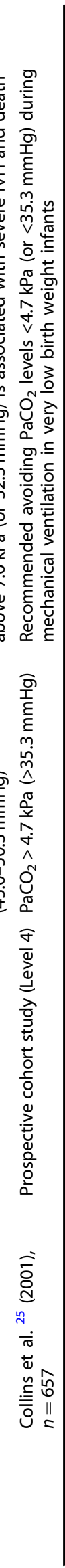 & 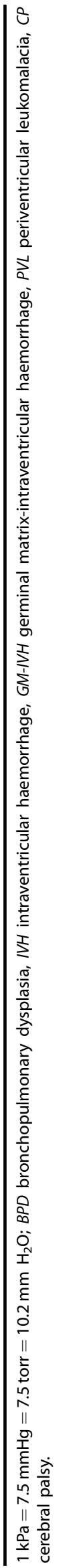 \\
\hline
\end{tabular}


statistically significant linear trend. It also found that with cumulative hypocapnia $\left(\mathrm{pCO}_{2}<4.7 \mathrm{kPa}=35.3 \mathrm{mmHg}\right)$ or prolonged ventilation as a ventilatory risk factor, the risk of $\mathrm{CP}$ increased by 7-9-fold as compared to ventilated newborns without any risk factors. In multivariate analysis of the same research, the only ventilation-associated risk factor that is statistically significant regardless of the multivariate model in which it is placed is cumulative hypocapnia. ${ }^{29}$

Hypercapnia. A randomised controlled trial carried out by Carlo et al among 220 extremely low birth weight infants found that permissive hypercapnia $\left(\mathrm{PaCO}_{2}>6.93 \mathrm{kPa}=52.0 \mathrm{mmHg}\right)$ did not significantly decrease mortality or incidence of BPD $(p=0.43)$. However, the use of mechanical ventilation at 36 weeks is significantly lesser in the minimally ventilated group as compared to the routine ventilation group $(p<0.01)$. This indicates that permissive hypercapnia might lower the severity of lung injury but not the incidence. ${ }^{29,30}$ Subramanian et al. conducted a multicentre observational cohort study of 425 newborns in Columbia, which examined the rates of BPD in low and extremely low birth weight infants (500-1499 g). They described a strong association between hypercapnia $\left(\mathrm{PaCO}_{2}>6.67 \mathrm{kPa}=50.0 \mathrm{mmHg}\right)$ and $\mathrm{BPD}$ in the first few days of life. This was based on the observation that the incidence of BPD was greater as compared to the group without hypercapnia $(p=0.024)$. The risk of BPD was increased even with permissive hypercapnia. ${ }^{16}$ In a secondary exploratory data analysis on 1316 extremely preterm infants of extremely low birth weight from the large multicenter trial Surfactant, Positive Pressure, and Oxygenation Randomised Trial (SUPPORT), Ambavlanan et al. ${ }^{31}$ found that higher maximum, average and fluctuation of $\mathrm{PaCO}_{2}$ correlated with an increased risk of BPD or death $(p=0.0002)$. Thome et al. ${ }^{32}$ found that mortality and incidence of moderate-tosevere BPD were significantly raised in hypercapnic extremely low birth weight premature newborns $(p<0.01)$ in a multicentre study. In concordance with these results, a retrospective cohort study of 268 extremely premature infants of very low and extremely low birth weight observed higher rates of severe IVH in infants with larger $\mathrm{pCO}_{2}$ fluctuations $(p=0.02) .^{33}$

Ambalavanan et al. ${ }^{31}$ in the secondary analysis of the SUPPORT trial (a large multicentre trial) found that higher peak $\mathrm{pCO}_{2}$ correlated with an increased risk of severe IVH/death $(p=0.029)$ and neurological impairment/death even at lower ranges of hypercapnia. Higher maximum $\mathrm{PaCO}_{2}$ was an independent risk factor for severe IVH/death even after statistical adjustment for illness severity. ${ }^{30,31}$ A retrospective cohort study by Zayek et al. investigated the role of mild to moderate hypercapnia (6.0-8.0 $\mathrm{kPa}=45.0-60.0 \mathrm{mmHg}$ ) and acidaemia in the occurrence of severe IVH in 580 extremely low birth weight infants within the first $48 \mathrm{~h}$ of life. They found that higher $\mathrm{pCO}_{2}\left(\mathrm{PaCO}_{2}>8.0 \mathrm{kPa}=\right.$ $60.0 \mathrm{mmHg}$ ) was significantly associated with increased rates of severe IVH as compared to normocapnic infants. ${ }^{34}$ Vela-Huerta et al. ${ }^{35}$ conducted a single centre retrospective case-control study on 28 cases of extremely low birth weight preterm infants with grade III or IV IVH and 55 controls and found that $\mathrm{PaCO}_{2}>7.3 \mathrm{kPa}$ $(>54.8 \mathrm{mmHg})$ was only associated with grade IV IVH. Köksal et al. ${ }^{36}$ found hypercapnia $\left(\mathrm{pCO}_{2}>8.0 \mathrm{kPa}\right.$ or $>60.0 \mathrm{mmHg}$ ) to be a risk factor for IVH $(p<0.0001)$ in 120 premature infants with very low and extremely low birth weight. In a retrospective study, Fabres et al. established that extreme $\mathrm{PaCO}_{2}$ levels and the magnitude of $\mathrm{pCO}_{2}$ fluctuation were good indicators of severe IVH in very low and extremely low birth weight preterm babies. They have also identified that maximal $\mathrm{PaCO}_{2}>8.0 \mathrm{kPa}(>60.0 \mathrm{mmHg})$ and time-weighted $\mathrm{PaCO}_{2}>7.0 \mathrm{kPa}(>52.5 \mathrm{mmHg})$ are associated with severe IVH. The optimal range of $\mathrm{pCO}_{2}$ derived by the team was $5.2-8.0 \mathrm{kPa}(39.0-60.0 \mathrm{mmHg})$ and at that range, there was only a $3 \%$ incidence of severe $\mathrm{IVH} .^{10}$

Waitz et al. explored the risk factors of IVH in extremely preterm neonates. Higher maximal $\mathrm{PaCO}_{2}$ was a risk factor for IVH 


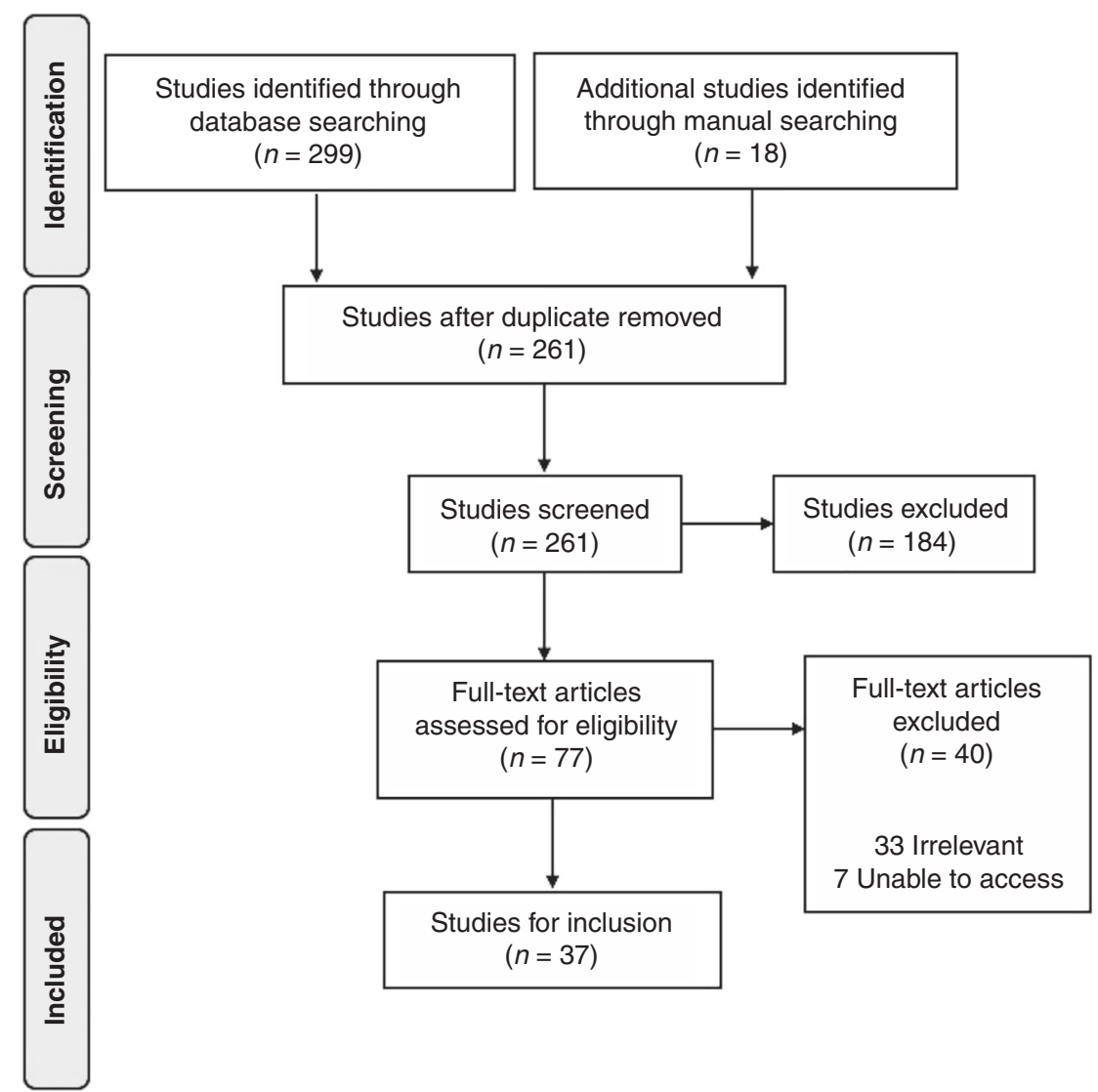

Fig. 1 PRISMA flowsheet: studies of Carbon Dioxide in Neonates.

$(p=0.001)$ and the risk increased by a factor of 1.04 for every $0.13 \mathrm{kPa}(0.98 \mathrm{mmHg}){ }^{14}$ The same study further quantified that moderate permissive hypercapnia $(7.3-8.7 \mathrm{kPa}=54.8-65.2$ $\mathrm{mmHg}$ ) was not associated with a higher incidence of severe IVH when compared to the normocapnic group $(5.3-7.7 \mathrm{kPa}=$ $39.8-57.8 \mathrm{mmHg}$ ). Ali et al. $^{37}$ stated that there was a significant independent association between hypercapnia and the development of Retinpathy of prematurity (ROP), making hypercapnia a significant variable of development of ROP.

\section{Neonatal encephalopathy}

Hypocapnia. Lopez Laporte et al. studied 198 newborns exposed to asphyxia and found a possible association between hypocapnia and the severity of the brain injury. They also highlighted that "asphyxiated" newborns treated with ventilation and hypothermia have higher incidences of brain injury. ${ }^{13}$

Moderate hypocapnia $(2.6-4.7 \mathrm{kPa}=19.5-35.3 \mathrm{mmHg})$ was not found to be a significant risk factor of severe disability and death in NE by Nadeem et al. ${ }^{38}$ or Hansen et al. ${ }^{39}$ Hansen et al. found no effect of moderate, severe hypocapnia or time-weighted cumulative hypocapnia on neurodevelopmental outcomes. However, Hansen and co-workers suggested that neonates with NE who are treated with therapeutic hypothermia should not be overventilated to prevent hypocapnia and its adverse effects. ${ }^{38,39}$

Pappas et al. found that minimum $\mathrm{pCO}_{2}$ defined as isolated severe hypocarbia, cumulative $\mathrm{pCO}_{2}<4.7 \mathrm{kPa}(35.3 \mathrm{mmHg})$ and larger $\mathrm{pCO}_{2}$ fluctuations in the first $16 \mathrm{~h}$ of life were associated with disability and death at 18-22 months in neonates that have NE. The greater the cumulative exposure, the worse the outcome and minimum $\mathrm{pCO}_{2}$ was the only significant predictor of negative outcome. $^{40}$

Consistent with the findings by Pappas et al., Linggapan et al. suggested that probability of an unfavourable outcome increases as $\mathrm{pCO}_{2}$ values decrease. In newborns with severe $\mathrm{NE}$, hypocapnia $\left(\mathrm{pCO}_{2}\right.$ between 2.7 and $5.3 \mathrm{kPa}=20.3-39.8 \mathrm{mmHg}$ ) was associated with a higher probability of unfavourable outcome as compared to those with moderate NE. ${ }^{4}$

Hypercapnia. A retrospective cohort study by Lopez Laporte ${ }^{13}$ et al. found that neither the magnitude of $\mathrm{CO}_{2}$ fluctuations nor hypercapnia were significant risk factors for brain injury in NE. Hypercapnia was not a significant risk factor for severe disability and death in infants with NE. ${ }^{38}$ A similar relationship was also illustrated in a study by Pappas et al., ${ }^{40}$ which reported that maximum $\mathrm{pCO}_{2}$ and cumulative exposure to hypercapnia were not significant predictors of disability or death. Although NE infants with cumulative $\mathrm{pCO}_{2}$ above the 50th percentile were more likely to have seizures and needed more time to achieve spontaneous respiration, only the time to spontaneous respiration of more than $10 \mathrm{~min}$ had a significant association with adverse outcomes. ${ }^{41}$ Hansen et al. ${ }^{39}$ retrospectively studied 23 neonates with moderate to severe NE treated with $72 \mathrm{~h}$ of hypothermia and it was found that those from the group with adverse neurodevelopmental outcomes had greater $\mathrm{PaCO}_{2}$ variability than those from the group with favourable neurodevelopmental outcomes. The hypoxic-ischaemic encephalopathy therapy optimization in neonates for better neuroprotection with inhaled $\mathrm{CO}_{2}$ (HENRIC) study, which involved 10 term infants, recently demonstrated that inhaled $5 \% \mathrm{CO}_{2}$ was feasible and safe for correcting hypocarbia in NE. ${ }^{41}$

Congenital diaphragmatic hernia. $\mathrm{CDH}$ is associated with pulmonary hypoplasia and respiratory distress at birth and infants with $\mathrm{CDH}$ frequently require mechanical ventilation following delivery. Abbas et al. found that neonates with $\mathrm{CDH}$ who remained hypercapnic $\left(\mathrm{PaCO}_{2}>9.6 \mathrm{kPa}>72.0 \mathrm{mmHg}\right)$ had poorer 
survival rates than those who were normocapnic $\left(\mathrm{PaCO}_{2}=5.2 \mathrm{kPa}\right.$ $=39.0 \mathrm{mmHg}$ ) after resuscitation $(p<0.001)$. However, hypercapnia may simply be a marker of more severe lung hypoplasia, thus explaining the increased mortality in this group. The study also investigated the impact of initial $\mathrm{PaCO}_{2}$ and best $\mathrm{PaCO}_{2}$ on survival rates and patients with an initial and best $\mathrm{PaCO}_{2}$ of $>8.0$ $\mathrm{kPa}(>60.0 \mathrm{mmHg})$ had higher mortality rates $(p=0.003$ and $p=$ 0.001 respectively). Best $\mathrm{PaCO}_{2}$ and $\mathrm{PaCO}_{2}$ after resuscitation are better predictors of neonatal survival compared to foetal lung volumes. A retrospective study by Bojanic et al. showed that survival rates were higher among term neonates with $\mathrm{CDH}$ who were treated according to a permissive hypercapnia protocol $(p=0.019)$. This study also observed that those with higher end-capillary partial pressure $\left(\mathrm{PcCO}_{2}\right)$ on admission had a lower probability of survival $(p=0.008)$, which raises the possibility of $\mathrm{PcCO}_{2}$ on admission being a good marker of survival prognostication. ${ }^{42}$

Permissive hypercapnia. A meta-analysis by Ma et al..$^{38}$ concluded that permissive hypercapnia did not have notable effects on IVH, PVL, NEC, ROP, mortality or air leaks in extremely low birth weight infants. Permissive hypercapnia also did not lead to elevated risks of $C P$, visual or hearing impairment nor did it decrease the risk of BPD. $^{43}$

A 2001 Cochrane review published by Woodgate and Davies included two randomised controlled trials. ${ }^{22}$ This review concluded that evidence did not support the use of permissive hypercapnia to prevent morbidity and mortality in newborns receiving mechanical ventilation, particularly BPD or death at 36 weeks, severe IVH and PVL. Although Brown et al. did not find a significant reduction in BPD in secondary analyses of randomised controlled trials when neonates were treated with mild hypercapnia $\left(6.0-7.2 \mathrm{kPa}=45.0-54.0 \mathrm{mmHg}\right.$ ), a mean $\mathrm{PaCO}_{2}$ of $7.0 \mathrm{kPa}$ $(52.5 \mathrm{mmHg})$ was found to be associated with severe IVH or death. ${ }^{9}$ Thome et al. ${ }^{44}$ found $\mathrm{PaCO}_{2}$ levels of $7.3-8.7 \mathrm{kPa}$ $(54.8-65.3 \mathrm{mmHg})$ were associated with higher mortality, neurodevelopmental impairment, and an increase in the combined outcome of mental impairment or death and higher $\mathrm{PaCO}_{2}$ levels in the first 3 days of life were associated with IVH by Waitz et al. ${ }^{14}$

\section{DISCUSSION}

Different definitions of hypo- and hypercapnia make it challenging to determine a standardised range of $\mathrm{CO}_{2}$ in neonates. ${ }^{45}$ Avoiding both hypocapnia and hypercapnia is optimal but there is not a definite range of optimal $\mathrm{CO}_{2}$. However, permissive hypercapnia within a limited range may be beneficial as higher alveolar $\mathrm{CO}_{2}$ increases $\mathrm{CO}_{2}$ elimination and stimulates the neonate's respiratory drive which facilitates weaning from mechanical ventilation. ${ }^{7}$ Similarly, severe hypercapnia should be avoided as it correlates with a higher IVH incidence. ${ }^{34,35,42} \mathrm{pCO}_{2}$ fluctuations may be more significantly associated with severe IVH than the mere presence of hypercapnia. ${ }^{31}$ Extremely preterm and very low birth weight infants may benefit from moderate permissive hypercapnia as it was not found to increase the incidence of IVH. ${ }^{14,46}$

\section{Hypocapnia}

Hypocapnia is detrimental and contributes to PVL development as it worsens cerebral blood flow dysregulation and exacerbate hypoxic-ischaemic white matter damage. ${ }^{5}$ Neonates are particularly vulnerable to hypocapnia at specific time periods and immaturity of respiratory control in the neonatal period could play a role ${ }^{47,48}$ and hypocapnia is associated with an increased risk of $\mathrm{CP}$ in ventilated low birth weight infants. Therefore, avoiding $\mathrm{pCO}_{2}<4.7 \mathrm{kPa}(35.3 \mathrm{mmHg})$ has been recommended as values below this were associated with brain injury $(35.3 \mathrm{mmHg}){ }^{29}$

Infants with NE may be able to tolerate hypercapnic states as it has not been shown to contribute to increased morbidity and mortality. ${ }^{13,40} \mathrm{NE}$ is frequently associated with hypocapnia. ${ }^{4}$ Hypocapnia increases lactate production (secondary to ischaemia from cerebral vasoconstriction), cerebral oxygen demand and neuronal excitability. Hypocapnia ${ }^{4}$ and $\mathrm{PaCO}_{2}$ variability ${ }^{38}$ are modifiable risk factors that may potentially help to improve the neurological outcomes. Therefore, a strategy aimed at lowering the risk of prolonged and severe hypocapnia are $\mathrm{CO}_{2}$ inhalation as described in the HENRIC study is attractive. ${ }^{41}$ Inconsistent results exist for $\mathrm{CDH}$, with Abbas et al. ${ }^{18}$ recommending normocapnia to optimise survival and Bojanic et al. ${ }^{42}$ proposing that permissive hypercapnia is protective. However, there is a paucity of data in this area and long-term effects and outcomes are unknown in children with $\mathrm{CDH}$ related to $\mathrm{PaCO}_{2}$ and the evidence from preterm data suggest early hypercapnia may be detrimental.

For hypocapnia, reported parameters for $\mathrm{CP}\left(\mathrm{pCO}_{2}<4.7 \mathrm{kPa}\right.$; $<35.3 \mathrm{mmHg}), \mathrm{NE}\left(\mathrm{PaCO}_{2}<3.3 \mathrm{kPa} ;<24.7 \mathrm{mmHg}\right)$ and $\mathrm{PVL}\left(\mathrm{PaCO}_{2}\right.$ $<4.67 \mathrm{kPa}$; $<35.0 \mathrm{mmHg}$ ) were identified. For hypercapnia, parameters mentioned for BPD $\left(\mathrm{pCO}_{2}>6.67 \mathrm{kPa} ;>50.0 \mathrm{mmHg}\right)$, IVH $\left(\mathrm{PaCO}_{2}>7.7-8.0 \mathrm{kPa} ;>57.8-60.0 \mathrm{mmHg}\right)$ and $\mathrm{CDH}\left(\mathrm{PaCO}_{2}>\right.$ $5.2 \mathrm{kPa} ;>39.0 \mathrm{mmHg}$ and $\mathrm{PcCO}_{2} \geq 8.7 \mathrm{kPa} ; \geq 65.3 \mathrm{mmHg}$ ) were described.

\section{Hypercapnia}

Permissive hypercapnia has not been validated nor have the safe upper limit of permissive hypercapnia been defined. Permissive hypercapnia is thought to reduce the risk of BPD and confer protection against volutrauma ${ }^{9}$ although results are equivocal. A randomised trial by Thome et al. ${ }^{17}$ found that BPD rates did not improve with moderate hypercapnia. In this trial ${ }^{17}$ higher permissive hypercapnia was compared to lower permissive hypercapnia with no normocapnic study group showing that higher $\mathrm{pCO}_{2}$ targets did not increase any benefit over mild permissive hypercapnia

A follow-up study by Thome et al. ${ }^{49}$ concluded that a higher $\mathrm{PaCO}_{2}$ target did not affect neurodevelopmental outcomes in extremely preterm infants. Moreover, Subramanian et al. ${ }^{16}$ suggested that permissive hypercapnia predisposes an infant to BPD. A possible explanation for this phenomenon could be that the benefits of low tidal volume may be offset by higher ventilator rates, thereby minimising the advantage of minimal ventilation in extremely preterm neonates. ${ }^{17}$ Not only does severe IVH and retinopathy not improve with moderate hypercapnia, ${ }^{17}$ it may actually increase the risk of IVH. A suggested mechanism is increased cerebral blood flow secondary to hypercapnia which leads to cerebral oedema, raised intracranial pressure and resultant haemorrhage. ${ }^{50}$ However, recent literature suggests that it is the ischaemia, secondary to hypocapnia, that causes a haemorrhage or an extension of the pre-existing haemorrhage following reperfusion of the ischaemic region. The length of ventilation has also been implicated in the effectiveness of permissive hypercapnia. Ryu et al. ${ }^{23}$ reviewed three trials and concluded that only neonates who received longer intervention (10 days) had reduced rates in BPD whilst shorter interventions yielded heterogeneous results. Extreme hyper- or hypocapnia and rapid fluctuations in $\mathrm{pCO}_{2}$ were detrimental to preterm infants especially in the first week of life. The optimal $\mathrm{pCO}_{2}$ goal in clinical practice is still undetermined, but tolerating modest hypercapnia $\left(\mathrm{pCO}_{2}<6.7 \mathrm{kPa}[50 \mathrm{mmHg}]\right)$ may be beneficial.

$\mathrm{CO}_{2}$ levels are known to influence immune and inflammatory signalling in cells, tissues, animals and humans. Hypercapnia can be either protective or deleterious depending on the context. The current view is that hypercapnia is harmful in the context of infection but may in fact be beneficial in the context of uncontrolled inflammation. ${ }^{1}$ Clinically, hypercapnia is associated with a higher hazard ratio for death in chronic obstructive pulmonary disease, ${ }^{51}$ higher ICU mortality in acute respiratory distress syndrome ${ }^{52,53}$ among adults. Given these adverse clinical outcomes, it may be surprising that hypercapnia is proposed to 
have anti-inflammatory effects and indeed was found to be protective in a recent clinical trial of "therapeutic hypercapnia" in single lung lobectomy patients. ${ }^{54}$ The molecular mechanisms underpinning $\mathrm{CO}_{2}$-dependent suppression of immune signalling are not fully elucidated but likely involve suppression of proinflammatory signalling cascades. The master-regulator of immune and inflammatory signalling, nuclear factor $\kappa B(N F \kappa B)$, has been implicated in both hypercapnia and hypercapnic acidosis. Cummins et al. ${ }^{55,56}$ have reported $\mathrm{CO}_{2}$-dependent modulation of the NFKB pathway on multiple levels including protein localisation, transcriptional activation and protein-protein interactions. The concept of NFKB sensitivity to $\mathrm{CO}_{2}$ levels is additionally supported by several studies from the Laffey lab ${ }^{57,58}$ and others. ${ }^{59}$ While $\mathrm{CO}_{2}$-dependent modulation of NFKB signalling is important in several cell types it is likely that other factors are also involved alone or in combination with $\mathrm{NFKB}$, including HSF$1,{ }^{60}$ FOXO3a $^{61}$ and CREB. ${ }^{62}$ Thus, $\mathrm{CO}_{2}$ represents a potentially modifiable factor with the potential to suppress damaging inflammatory signalling in the lung. However, this benefit does not extend to neonates who have sustained ventilator-associated injuries as hypercapnic acidosis impedes plasma membrane repair. $^{61,63}$

This review was limited by the research design utilised by the studies included. Some studies comprised small cohorts with multiple clinical morbidities making it statistically underpowered and thus cannot make associations or establish causal relationships. The retrospective nature of some studies also affects the credibility of the information presented. Different ventilation settings and different sources of blood gas samples (e.g. arterial, capillary and venous) across the cohort can affect the accuracy of the results obtained. For example, capillary and venous samples may artificially increase $\mathrm{pCO}_{2}$ values and overestimate the effects hypocapnia and hypercapnia have on neonates. Different $\mathrm{CO}_{2}$ measurement methods (e.g. blood gas, capnography) also contribute to variation in the results obtained. Lastly, fixed interval monitoring rather than continuous monitoring may overlook important $\mathrm{CO}_{2}$ trends.

Based on the literature review performed, it appears that $\mathrm{pCO}_{2}$ levels of approximately $5-7 \mathrm{kPa}(37.5-52.5 \mathrm{mmHg})$ may be safe for neonates requiring ventilatory support. Intervention to therapeutically alter carbon dioxide has been suggested in the recent HENRIC study which demonstrated the use of $\mathrm{CO}_{2}$ insufflation to prevent hypocarbia in NE. While the research for safe $\mathrm{O}_{2}$ ranges in preterm and term infants is well underway, the same advancement is required for $\mathrm{CO}_{2}$. Contradictory findings highlight the need for rigorous evidence to establish the role of permissive hypercapnia in clinical practice and if beneficial, the safe upper limit of permissive hypercapnia. Until safe ranges have been clearly defined, this ventilation strategy should be used with caution.

\section{ACKNOWLEDGEMENTS}

E.J.M. is funded by the Health Research Board, Ireland; E.P.C. is funded by Science Foundation Ireland (15/CDA/3490)

\section{AUTHOR CONTRIBUTIONS}

S.K.W. contributed to acquisition, analysis and interpretation of data; drafting and revising the article; and approving the final version. M.C., A.B., J.T. and M.O. contributed to design; acquisition, analysis and interpretation of data; drafting and revising the article; and approving the final version. J.A. and N.L. contributed to design; analysis and interpretation of data; revising the article; and approving the final version; T.H., M.M.G. and E.P.C. contributed to analysis and interpretation of data; revising the article; and approving the final version. J.M. contributed to design; acquisition, analysis and interpretation of data; revising the article; and approving the final version. E.J.M. contributed to conception and design; acquisition, analysis and interpretation of data; drafting and revising the article; and approving the final version.

\section{FUNDING}

Open Access funding provided by the IReL Consortium.

\section{ADDITIONAL INFORMATION}

Competing interests: The authors declare no competing interests.

Consent: Patient consent was not required for this review of the literature

Publisher's note Springer Nature remains neutral with regard to jurisdictional claims in published maps and institutional affiliations.

\section{REFERENCES}

1. Cummins, E. P., Strowitzki, M. J. \& Taylor, C. T. Mechanisms and consequences of oxygen and carbon dioxide sensing in mammals. Physiol. Rev. 100, 463-488 (2020).

2. Kikuchi, R. et al. Hypercapnic tumor microenvironment confers chemoresistance to lung cancer cells by reprogramming mitochondrial metabolism in vitro. Free Radic. Biol. Med. 134, 200-214 (2019).

3. Cummins, E. P. \& Keogh, C. E. Respiratory gases and the regulation of transcription. Exp. Physiol. 101, 986-1002 (2016).

4. Lingappan, K., Kaiser, J. R., Srinivasan, C. \& Gunn, A. J. Relationship between $\mathrm{PCO}_{2}$ and unfavorable outcome in infants with moderate-to-severe hypoxic ischemic encephalopathy. Pediatr. Res. 80, 204-208 (2016).

5. Liu, J., Li, J., Qin, G. L., Chen, Y. H. \& Wang, Q. Periventricular leukomalacia in premature infants in mainland China. Am. J. Perinatol. 25, 535-540 (2008).

6. Zhou, W. \& Liu, W. Hypercapnia and hypocapnia in neonates. World J. Pediatr. 4, 192-196 (2008)

7. Thome, U. H. \& Ambalavanan, N. Permissive hypercapnia to decrease lung injury in ventilated preterm neonates. Semin. Fetal Neonatal Med. 14, 21-27 (2009).

8. Vanderhaegen, J. et al. The effect of changes in $\mathrm{tPCO}_{2}$ on the fractional tissue oxygen extraction-as measured by near-infrared spectroscopy-in neonates during the first days of life. Eur. J. Paediatr. Neurol. 13, 128-134 (2009).

9. Brown, M. K. et al. Incidence of hypocapnia, hypercapnia, and acidosis and the associated risk of adverse events in preterm neonates. Respir. Care 63, 943-949 (2018).

10. Fabres, J., Carlo, W. A., Phillips, V., Howard, G. \& Ambalavanan, N. Both extremes of arterial carbon dioxide pressure and the magnitude of fluctuations in arterial carbon dioxide pressure are associated with severe intraventricular hemorrhage in preterm infants. Pediatrics 119, 299-305 (2007).

11. Kaiser, J. R., Gauss, C. H., Pont, M. M. \& Williams, D. K. Hypercapnia during the first 3 days of life is associated with severe intraventricular hemorrhage in very low birth weight infants. J. Perinatol. 26, 279-285 (2006).

12. Thome, U. H. \& Carlo, W. A. Permissive hypercapnia. Semin Neonatol. 7, 409-419 (2002).

13. Lopez Laporte, M. A. et al. Association between hypocapnia and ventilation during the first days of life and brain injury in asphyxiated newborns treated with hypothermia. J. Matern. Fetal Neonatal Med. 32, 1312-1320 (2019).

14. Waitz, M. et al. Risk factors associated with intraventricular hemorrhage in preterm infants with $</=28$ weeks gestational age. Klin. Padiatr. 228, 245-250 (2016).

15. Weeke, L. C. et al. Severe hypercapnia causes reversible depression of aEEG background activity in neonates: an observational study. Arch. Dis. Child Fetal Neonatal Ed. 102, F383-F388 (2017).

16. Subramanian, S., El-Mohandes, A., Dhanireddy, R. \& Koch, M. A. Association of bronchopulmonary dysplasia and hypercarbia in ventilated infants with birth weights of 500-1,499 g. Matern Child Health J. 15, S17-S26 (2011).

17. Thome, U. H. et al. Permissive hypercapnia in extremely low birthweight infants (PHELBI): a randomised controlled multicentre trial. Lancet Respir. Med. 3, 534-543 (2015).

18. Abbas, P. I. et al. Persistent hypercarbia after resuscitation is associated with increased mortality in congenital diaphragmatic hernia patients. J. Pediatr. Surg. 50, 739-743 (2015).

19. Ramanathan, R. \& Sardesai, S. Lung protective ventilatory strategies in very low birth weight infants. J. Perinatol. 28, S41-S46 (2008).

20. Avery, M. E. et al. Is chronic lung disease in low birth weight infants preventable? A survey of eight centers. Pediatrics 79, 26-30 (1987).

21. Ambalavanan, N. \& Carlo, W. A. Hypocapnia and hypercapnia in respiratory management of newborn infants. Clin. Perinatol. 28, 517-531 (2001).

22. Mariani, G., Cifuentes, J. \& Carlo, W. A. Randomized trial of permissive hypercapnia in preterm infants. Pediatrics 104, 1082-1088 (1999).

23. Ryu, J., Haddad, G. \& Carlo, W. A. Clinical effectiveness and safety of permissive hypercapnia. Clin. Perinatol. 39, 603-612 (2012). 
24. Jankov, R. P. \& Tanswell, A. K. Hypercapnia and the neonate. Acta Paediatr. 97, 1502-1509 (2008)

25. Hutton, B. et al. The PRISMA extension statement for reporting of systematic reviews incorporating network meta-analyses of health care interventions: checklist and explanations. Ann. Intern. Med. 162, 777-784 (2015).

26. Stroup, D. F. et al. Meta-analysis of observational studies in epidemiology, a proposal for reporting. JAMA 283, 2008-2012 (2000).

27. Veritas Health Innovation M, Australia. Covidence systematic review software. www.covidence.org (2019).

28. Winona State University Darrell W. Krueger Library, Minnesota. Evidence Based Practice Toolkit. https://libguides.winona.edu/c.php?g=11614\&p=61584\#: : text=Levels\%20of\%20evidence\%20(sometimes\%20called,or\%20strength)\%20of \%20recommendation.\%22 (2020).

29. Collins, M. P., Lorenz, J. M., Jetton, J. R. \& Paneth, N. Hypocapnia and other ventilation-related risk factors for cerebral palsy in low birth weight infants. Pediatr. Res. 50, 712-719 (2001).

30. Carlo, W. A. et al. Minimal ventilation to prevent bronchopulmonary dysplasia in extremely-low-birth-weight infants. J. Pediatr. 141, 370-374 (2002).

31. Ambalavanan, $\mathrm{N}$. et al. $\mathrm{PaCO}_{2}$ in surfactant, positive pressure, and oxygenation randomised trial (SUPPORT). Arch. Dis. Child Fetal Neonatal Ed. 100, F145-F149 (2015).

32. Thome, $\mathrm{U}$. $\mathrm{H}$. et al. Influence of $\mathrm{PCO}_{2}$ control on clinical and neurodevelopmental outcomes of extremely low birth weight infants. Neonatology 113, 221-230 (2018).

33. Altaany, D., Natarajan, G., Gupta, D., Zidan, M. \& Chawla, S. Severe intraventricular hemorrhage in extremely premature infants: are high carbon dioxide pressure or fluctuations the culprit? Am. J. Perinatol. 32, 839-844 (2015).

34. Zayek, M. M. et al. Acidemia versus hypercapnia and risk for severe intraventricular hemorrhage. Am. J. Perinatol. 31, 345-352 (2014).

35. Vela-Huerta, M. M., Amador-Licona, M., Medina-Ovando, N. \& Aldana-Valenzuela, C. Factors associated with early severe intraventricular haemorrhage in very low birth weight infants. Neuropediatrics 40, 224-227 (2009).

36. Koksal, N., Baytan, B., Bayram, Y. \& Nacarkucuk, E. Risk factors for intraventricular haemorrhage in very low birth weight infants. Indian J. Pediatr. 69, 561-564 (2002).

37. Ali, A. A., Gomaa, N. A. S., Awadein, A. R., Al-Hayouti, H. H. \& Hegazy, A. I. Retrospective cohort study shows that the risks for retinopathy of prematurity included birth age and weight, medical conditions and treatment. Acta Paediatr. 106, 1919-1927 (2017).

38. Nadeem, M., Murray, D., Boylan, G., Dempsey, E. M. \& Ryan, C. A. Blood carbon dioxide levels and adverse outcome in neonatal hypoxic-ischemic encephalopathy. Am. J. Perinatol. 27, 361-365 (2010).

39. Hansen, G., Al Shafouri, N., Narvey, M., Vallance, J. K. \& Srinivasan, G. High blood carbon dioxide variability and adverse outcomes in neonatal hypoxic ischemic encephalopathy. J. Matern Fetal Neonatal Med. 29, 680-683 (2016).

40. Pappas, A. et al. Hypocarbia and adverse outcome in neonatal hypoxic-ischemic encephalopathy. J. Pediatr. 158, 752-8 e1 (2011).

41. Szakmar, E. et al. Neonatal encephalopathy therapy optimization for better neuroprotection with inhalation of $\mathrm{CO}_{2}$ : the HENRIC feasibility and safety trial. Pediatr. Res. 87, 1025-1032 (2019).

42. Bojanic, K. et al. Survival of outborns with congenital diaphragmatic hernia: the role of protective ventilation, early presentation and transport distance: a retrospective cohort study. BMC Pediatr. 15, 155 (2015).

43. Ma, J. \& Ye, H. Effects of permissive hypercapnia on pulmonary and neurodevelopmental sequelae in extremely low birth weight infants: a meta-analysis. Springerplus 5, 764 (2016).

44. Thome, U. H. et al. Outcome of extremely preterm infants randomized at birth to different $\mathrm{PaCO}_{2}$ targets during the first seven days of life. Biol. Neonate. 90, 218-225 (2006)

45. Molloy, E. J. \& Cummins, E. P. Carbon dioxide as a drug in neonatology. Pediatr. Res. https://doi.org/10.1038/s41390-020-1051-y (2020).

46. Hagen, E. W., Sadek-Badawi, M., Carlton, D. P. \& Palta, M. Permissive hypercapnia and risk for brain injury and developmental impairment. Pediatrics 123, 583-589 (2008).
47. Resch, B. et al. Episodes of hypocarbia and early-onset sepsis are risk factors for cystic periventricular leukomalacia in the preterm infant. Early Hum. Dev. 88, 27-31 (2012).

48. Santosh, K. K. Apnea in neonates-concepts and controversies. Progressing Asp. Pediatrics Neonatol. 2, 130-134 (2019).

49. Thome, U. H. et al. Neurodevelopmental outcomes of extremely low birthweight infants randomised to different $\mathrm{PCO}_{2}$ targets: the PHELBI follow-up study. Arch. Dis. Child Fetal Neonatal Ed. 102, F376-F382 (2017).

50. Skouteli, H. N. et al. Arterial blood gas derangements associated with death and intracranial hemorrhage in premature babies. J. Perinatol. 8, 336-341 (1988).

51. Ahmadi, Z., Bornefalk-Hermansson, A., Franklin, K. A., Midgren, B. \& Ekstrom, M. P. Hypo- and hypercapnia predict mortality in oxygen-dependent chronic obstructive pulmonary disease: a population-based prospective study. Respir. Res. 15, 30 (2014)

52. Nin, N. et al. Severe hypercapnia and outcome of mechanically ventilated patients with moderate or severe acute respiratory distress syndrome. Intensive Care Med. 43, 200-208 (2017).

53. Laserna, E. et al. Hypocapnia and hypercapnia are predictors for ICU admission and mortality in hospitalized patients with community-acquired pneumonia. Chest 142, 1193-1199 (2012).

54. Gao, W., Liu, D. D., Li, D. \& Cui, G. X. Effect of therapeutic hypercapnia on inflammatory responses to one-lung ventilation in lobectomy patients. Anesthesiology 122, 1235-1252 (2015).

55. Cummins, E. P. et al. NF-kappaB links $\mathrm{CO}_{2}$ sensing to innate immunity and inflammation in mammalian cells. J. Immunol. 185, 4439-4445 (2010).

56. Keogh, C. E. et al. Carbon dioxide-dependent regulation of NF-kappaB family members RelB and p100 gives molecular insight into $\mathrm{CO}_{2}$-dependent immune regulation. J. Biol. Chem. 292, 11561-11571 (2017).

57. Contreras, M. et al. Hypercapnic acidosis attenuates ventilation-induced lung injury by a nuclear factor-kappaB-dependent mechanism. Crit. Care Med. 40, 2622-2630 (2012).

58. O'Toole, D. et al. Hypercapnic acidosis attenuates pulmonary epithelial wound repair by an NF-kappaB dependent mechanism. Thorax 64, 976-982 (2009).

59. Taylor, C. T. \& Cummins, E. P. Regulation of gene expression by carbon dioxide. J. Physiol. 589, 797-803 (2011)

60. Lu, Z. et al. A role for heat shock factor 1 in hypercapnia-induced inhibition of inflammatory cytokine expression. FASEB J. 32, 3614-3622 (2018).

61. Jaitovich, A. et al. High $\mathrm{CO}_{2}$ levels cause skeletal muscle atrophy via AMPactivated kinase (AMPK), FoxO3a protein, and muscle-specific Ring finger protein 1 (MuRF1). J. Biol. Chem. 290, 9183-9194 (2015).

62. Townsend, P. D. et al. Stimulation of mammalian G-protein-responsive adenylyl cyclases by carbon dioxide. J. Biol. Chem. 284, 784-791 (2009).

63. Doerr, C. H. et al. Hypercapnic acidosis impairs plasma membrane wound resealing in ventilator-injured lungs. Am. J. Respir. Crit. Care Med. 171, 1271-1277 (2005).

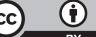

Open Access This article is licensed under a Creative Commons Attribution 4.0 International License, which permits use, sharing, adaptation, distribution and reproduction in any medium or format, as long as you give appropriate credit to the original author(s) and the source, provide a link to the Creative Commons license, and indicate if changes were made. The images or other third party material in this article are included in the article's Creative Commons license, unless indicated otherwise in a credit line to the material. If material is not included in the article's Creative Commons license and your intended use is not permitted by statutory regulation or exceeds the permitted use, you will need to obtain permission directly from the copyright holder. To view a copy of this license, visit http://creativecommons. org/licenses/by/4.0\%.

(c) The Author(s) 2021 